\title{
How Technology Life Cycles Increase the Financial Position of the Firm
}

\author{
James Maxwell \\ Lincoln Memorial University \\ Kelsey Metz \\ Lincoln Memorial University
}

\begin{abstract}
Businesses need to understand the importance of technology life cycles for increasing their financial position. It is extremely important to understand technology life cycle approaches for gaining competitive advantage and increasing the value of the firm. The technology life cycle seeks to predict the adoption, acceptance, and eventual decline of new technological innovations. Understanding and effectively estimating technology life cycle allows for a more accurate reading of whether and when research and development costs will be offset by profits. The purpose of this paper is to provide a review of the theory, and to discuss the continued relevance of technology life cycles as they relate to competitive advantage and improved financial performance.
\end{abstract}

Keywords: technology, life cycle, innovation

\section{INTRODUCTION}

The business world is continually progressing due to improvements in technology. As an example, it is almost impossible to obtain a job that lacks computer interface within today's society. This reality differs substantially from a quarter-century ago when computer-use by working professionals was not guaranteed. As such, this paper will discuss the continued importance of technology innovation, adoption, and deployment, and how firms can implement the use of technology life cycle models to aid in financial performance. Further, the impact of technological innovations on the United States economy will also be discussed.

\section{NEW ERA}

Throughout the generations, technology has evolved immensely. While the Silent Generation knew nothing or very little about the concept of computers, the following generation of Baby Boomers have grown to possess baseline computer knowledge. Subsequently, Generation X was largely raised knowing about computers, and have since developed an advanced computer skillset due to workforce requirements. The most current generation of workforce members, Millennials, were raised using computers and related products, and must now maintain a heightened level of computer competence to be professionally competitive. Aside from the use of computers for professional purposes, computers are now also used multiple times per day for personal reasons largely related to the attainment of information. Thus, our living 
within the Age of Information (Kosta et al., 2017). We know of no other way to survive than with our iPhones, tablets, laptops, and other digital devices. While the current generation is undeniably dependent upon modern technology, many individuals maintain a certain level of hesitation when considering the purchase of a newly introduced technological innovation. This hesitation is often attributed to the high monetary cost and related uncertainty of the potential adoption (Rogers, 2003). However, after a few months on the market, new product prices tend to fall, and the consumer may become more interested in finalizing the purchase decision. As for businesses, the decision to pursue the use of a new technology is much more complex as investment goes far beyond a single transaction. A business's investment in the adoption or creation of a new technology is often substantial, and, therefore, must be approached in a highly methodical manner.

\section{THE NEED FOR A LIFE CYCLE APPROACH}

Due to the introduction of numerous technological advances within the $20^{\text {th }}$ and $21^{\text {st }}$ centuries, many businesses had to determine a way to decipher the "good" new technologies from the "bad" new technologies. These companies had to formulate a way to make the decision-making process easier when seeking to develop or introduce new technological products or processes. While there are several ways that this can be accomplished, many companies chose to adopt a technology life cycle (TLC) approach. A technology life cycle approach, or model, is used to aid in the strategic management of technology. This concept visually depicts a technology's progression by graphing an organization's expended effort on a technology against the technology's obtained performance. Foster (1986) states that effort expended and obtained performance should be measured by quantifiable variables to more accurately estimate the amount of effort that is needed to obtain specific levels of performance within future technology cycles and predictive models. In graphing these items on the $\mathrm{X}$ and $\mathrm{Y}$ axes, respectively, a technology will fall into the category of Embryonic, Growth, Maturity, or Ageing (Foster, 1986). The Embryonic section of the graph suggests that an organization has expended little effort on the technology, thus performance obtained is also low. The Embryonic Stage infers that a technology is currently undergoing research and development (R\&D), or that the initial product has been recently introduced to the market. The Growth section infers that effort expended on the technology has increased, therefore obtained performance strongly increases due to the incremental innovations that improve the technology and its appeal within the market. The Maturity section communicates that effort expended has continued to progress, yet the performance obtained begins to slow and stabilize, often reaching an apex, as enhancing product-specific innovations become less frequent. The Ageing or Decline phase conveys that significant effort on behalf of the business has been expended on the examined technology, and the performance obtained has reached its limit. Within this phase, the technology's applicability is has likely declined, and a newer disruptive technology has emerged. With this new technological introduction, the cycle begins again. Graphically, this cycle often forms an S-shaped curve due to the appearance of sinusoidal line that results from the described pattern.

In using technology life cycle models for the strategic management of technology, many firms will apply the discussed s-curve model to determine the developmental stage of a currently used technology. In understanding the position of the technology, businesses can more accurately determine whether they should be investing in the creation or acceptance of a technology, investing in the improvement of the a current technology, reducing current investments due to capped performance levels, or actively seeking to adopt or create a replacement technology (Foster, 1986). As such, the use of a technology life cycle method can aid firm performance and decision-making by providing clear entry and exit criteria, as well as benefits relating to more effective and repeatable transition strategies. The model can also aid in the more decisive use of materials, skills, and human resources. As such, businesses can use this model to provide a greater level of clarity when discussing or justifying decision-making with stakeholders.

While the construction of an s-curve may require the collection of ample quantitative data, an accurate model has proven to maintain strong predictive capabilities within several industries including agriculture, transportation, energy, and information technology (Nieto et al., 1998; Taylor \& Taylor, 2012). Due to the continued introduction of disruptive technological innovations such as blockchain technology, the Internet 
of Things (IoT), 3D printing, and artificial intelligence, the understanding and applicability of technology life cycles maintains relevance within today's business environment (Bughin \& Woetzel, 2020; Forbes Technology Council, 2020; Frizzo-Barker et al., 2020). Businesses who do not actively seek to implement or introduce new technologies are likely to fall behind their competitors who proactively adopt and deploy updated processes and products (Hao \& Song, 2016). This occurs as improved processes lead to greater efficiency and resulting output. Similarly, up-to-date market ready products are needed as consumers consistently pursue new technological products and innovations for the purposes of convenience, entertainment, personal efficiency, and more. The use of technological innovations for increased productivity and heightened sales levels will be discussed in following sections.

\section{Theory of Technological Life Cycle}

In addition to Richard Foster's acclaimed s-curve model, Tushman and Anderson (1986) discussed the theory behind the occurrence of technological life cycles and their relation to disruptive technologies. The term disruptive technology refers to the introduction of an advancement that significantly changes, or differs from, the industry accepted norm. Tushman and Anderson (1986) describe disruption as a technological discontinuity that is so significant that no change in scale, efficiency, or design could make the older technology competitive with the newly introduced technology. The appearance of a technological disruption marks the start of a new technology life cycle. Anderson and Tushman (1990) describe a cycle that is similar to the one described by Foster (1986). This cycle begins with the occurrence of a technological disruption that causes the subsequent discontinuation of a standardized technology. Following the appearance of the disruption, an era of ferment commences as the experimental technology opens a new product class wherein product variations compete for dominance. Within this stage, technology adoption slowly ensues. Once the technology's dominant design emerges, the technology is absorbed more rapidly. Following the wide acceptance of the technological product, an era of incremental change occurs wherein smaller, incremental improvements enhance the technology. Once all foreseeable incremental innovations have been realized, a new technological disruption is likely to occur, and the process will begin once more (Anderson \& Tushman, 1990).

Within these various technological life cycle stages, technologies may be categorized as the following: Bleeding Edge, Leading Edge, State of the Art, Dated and Obsolete. During the Bleeding Edge stage, the technology shows high potential but has not demonstrated value or settled down into any kind of compromise. The Leading Edge classification occurs when a technology has proven itself in the marketplace but is still new enough that it may be difficult to find knowledgeable personnel to implement it or support it. The State of the Art stage occurs when everyone agrees that a particular technology is the right solution to an overarching problem. A technology is considered to be Dated when it is still useful, but a replacement Leading Edge technology is readily available. A technology is categorized as Obsolete when it has been superseded by a newer State of the Art technology (Tushman \& Anderson, 1986).

\section{Theory of Technology Acceptance}

While technology life cycles seek to aid firms in the strategic management of created or implemented technologies, product life cycles seek to examine product adoption among consumers. The product life cycle maintains the four stages of Introduction, Growth, Maturity, and Decline (Levitt, 1965). A product's position within one of these categories can be determined by continually graphing sales volume against time. The sales levels of a related product or technology relay consumer acceptance. In seeking to explain the phenomenon behind consumer acceptance of technology, Fred Davis, Richard Bagozzi, and Paul Warshaw (1989) developed the Technology Acceptance Model (TAM). The Technology Acceptance Model is an information systems theory that models how users come to accept and use a technology. The model suggests that when users are presented with a new software package or technological device, a number of factors will influence their decision-making. Primary influential adoption factors, however, were concluded to be perceived usefulness and perceived ease of use (Davis et al., 1989). Consumers' perceived ease of use increases in relation to the product life cycle and Everett Rogers' Diffusion of Innovations Theory. This occurs as heightened sales levels and coordinating widespread adoption of an innovation leads 
late majority-classified consumers to believe that a technology is easy to use, thus influencing their belated purchase decision (Rogers, 2003).

\section{TECHNOLOGY, PRODUCTION, AND THE ECONOMY}

Technological advancements have the power to improve businesses' financial performance, as well the economy as a whole. Edward Lazear, Professor of Economics at Stanford - Graduate School of Business, states, "There are two ways to achieve economic growth: Add population or make people more productive," (Snyder, 2019, para. 15). As the United States birthrate has continued to steadily decline, the latter must be accomplished (World Development Indicators, n.d.).

In examining the established relationship between technology, production, and the economy, it has been determined that technological advancements enhance productivity by efficiently increasing output (Çalışkan, 2015). Therefore, when output is increased, economic outcomes improve as the private and public sectors are enabled to consume a larger amount of goods and services. As a result of heightened consumption and consumer spending, businesses are more likely to invest their earnings into workforce expansion. In turn, employees' newly earned wages lead to higher household income levels, and, ultimately, an improved standard of living as estimated by the GDP per capita (Broughel \& Thierer, 2019). Additionally, in using more efficient production processes to make goods readily available within the marketplace, the gross domestic product (GDP) is improved as more products are produced annually. In using technological innovations to improve business productivity and output, businesses may use new technologies and innovations to manage their practices and processes in a more efficient manner. Introduced or improved technologies can effectively aid in the efficient management of employees, inventories, supply chains, product design, and more. The resulting improvement or elimination of inefficient production processes thus leads to enhanced profitability and financial performance.

In addition to improving the GDP through productivity and a resulting influx of assorted market-ready products, the occurrence of technological innovations can also influence consumer spending due to the purchases that result directly from the introduction of a new or improved technological product. As mentioned, new technological products often encounter a cyclical period related to consumer understanding and acceptance, however, once consumers have collectively decided to adopt a product, they will put forth the money to do so. This increase in spending benefits individual firms' financial performance, as well as the macroeconomy and GDP. The GDP is positively affected as this economic indicator considers the private consumption variable within the calculation. Likewise, if the technological advancement is adopted by government entities, the GDP would also be positively affected. Such was the case with the introduction and use of computers, smartphones, tablets, and various software packages within the workplace.

The United States' market-driven economy is one that fosters and encourages technological innovation. This occurs as unplanned economic systems allow for goods and services to be produced based on the forces of supply and demand (Gregory \& Stuart, 2004). As the government does not regulate or oversee the production and distribution of goods and services, technological advancements occur as people are free to present innovative ideas and products within the marketplace. Motivation for the introduction of innovative goods and services exists as producers are rewarded monetarily if their items are accepted and adopted by consumers. The United States' innovative atmosphere was further propelled in the 1990's due largely in part to the creation of the World Wide Web in 1989 (Choudhury, 2014). The combined adoption of personal computers, the Internet, and the World Wide Web allowed for the widespread exchange of ideas and an extensive collaborative network which arose on a global scale. As such, heightened information accessibility and resulting technological innovation led the United States economy to achieve performance levels which were unseen for a generation (Weller, 2002). The continual influxes in technology, which were put into motion by the information-oriented advancements of the 1990's, have subsequently aided in an approximate increase in nominal GDP from \$5.96 trillion in 1990 to \$21.43 trillion in 2019. Similarly, the approximated real GDP has increased from $\$ 9.37$ trillion in 1990 to $\$ 19.10$ trillion in 2019 (Gross Domestic Product, n.d.). The United States GDP is expected to drop during 2020 due to the COVID-19 pandemic (Gross Domestic Product, 2020). 


\section{TECHNOLOGICAL INNOVATION}

Technological innovation is inherent to competitive success. Innovation leads to improved technologies through the creative development and application of new ideas (Kogan et al., 2017). As established, the occurrence technological advancements the lead to improved productivity, sales levels, firm-specific financial performance, and ultimately economic growth. Technological innovation may originate through a singular inventor, or by way of a collaborative network. Examples of collaborative networks include joint ventures, research associations, and informal networks. In high-technology sectors collaborative networks are very important because individual firms rarely possess all the resources and capabilities that are necessary to succeed (Daft, 2021). For an organization to be successful with innovative activity and the resulting creation and implementation of innovations, a firm-specific innovation strategy is required. Innovation strategies should be unique as those belonging to other firms cannot be directly replicated due to organizational differences. Successful innovation strategies should consider the firm as a whole by promoting interdepartmental collaboration, knowledge-sharing, and experimentation for the purpose for formulating new and improved ideas that optimize business performance (Pisano, 2015). These requirements mimic those needed by a successful external collaborative network.

There are several dimensions used to categorize innovations and to help clarify how different innovations offer different opportunities on producers, users, and regulators (Schilling, 2017). Various types of innovations include product and process innovations, incremental and radical innovations, competence-enhancing and competence-destroying innovations, and component and architectural innovations. Product innovations are embodied in the outputs of an organization through its goods or services. Process innovations are innovations in the way an organization conducts its business, such as, the techniques of producing or how they market goods or services. Product innovations can enable process innovations and, vis-à-vis, process innovations can enable product innovations. Incremental innovations may involve only a minor change from existing practices. The radical innovation is the degree to which it is new and different from the previous existing product and processes. A radical innovation is relative meaning that it can change over time or with respect to different observers. Competence-Enhancing innovations build on the firm's existing knowledge base. Competence-Destroying innovations render a firm's existing competencies obsolete. It depends on the firm's perspective to decide whether their innovations are competence-enhancing or competence-destroying. A component innovation, also referred to as a modular innovation, entails change to one or more components of a product system without significantly affecting the overall design. An architectural innovation entails changing the design of the system or changing the way that the components interact.

\section{CHOOSING INNOVATIVE PROJECTS}

There are different methods of choosing innovation projects. Selection methods can be informal or highly structured. Also, they can be entirely qualitative, strictly quantitative, or a mix of both. Usually firms will use a combination of methods to completely evaluate the potential of the innovation project.

\section{Quantitative Methods}

Commonly used quantitative methods for choosing innovative projects include the Discounted Cash Flow and Real Options approaches. In Discounted Cash Flow, the net present value of an investment project is calculated by examining discounted expected cash inflows against discounted cash outlays for the purpose of determining estimated profitability. The Internal Rate of Return (IRR) is the discount that makes the net present value of an investment zero. Discounted Cash Flow analyses often produce accurate financial estimates as they consider the timing of an investment, as well as the time value of money.

A Real Options approach applies a stock option model to non-financial resource investments. An example of this method would be research and development (R\&D) capability and license to commercialize technology. There are limitations to real options models, however, as many innovation projects do not conform to the same capital market assumptions as the real options models. Additionally, real options 
models may not acquire options at a small price, as they may require full investment before its known whether the technology will be successful.

\section{Qualitative Methods}

Most firms use qualitative methods when factors in the development of projects are difficult to quantify. Screening questions are a type of qualitative method that is often employed. Screening questions may be used to assess different dimensions of the project decision that include the role of the customer, role of the capabilities, and the project timing and cost. The role of the customer would be market, ease of use, distribution and pricing. The role of capabilities would be future capabilities and competitors' capabilities.

Another commonly used qualitative method includes mapping the company research and development portfolio. This method emphasizes balance of the different types of projects and coordinating resource availability. Additionally, qualitative methods such as Aggregate Project Planning (APP) may be used. The Aggregate Project Planning method examines the goals and objectives of the company, and how these items may be accomplished through individual projects. Once relevance is established, projects can then be placed into the categories of Breakthrough Projects, Platform Projects, Derivative Projects, Advanced R\&D Projects, and Partnered Projects. A Breakthrough project incorporates new revolutionary technologies into a commercial application. A Platform project is not revolutionary, however, offers fundamental improvements over proceeding generations of products. A Derivative project uses incremental improvements and a variety of design features. A Derivative project pays off the fastest and it helps service the firm's short-term cash flow needs. Advanced R\&D projects include the development of cutting-edge technologies. While these projects have no immediate commercial application and take longer to pay off, a successful advanced R\&D project will put the firm in a position to be a technological leader.

Innovative ideas can also be ranked on different dimensions using a Q-Sort Technique developed by William Stephenson in the 1930s. First, you place innovative ideas on individual cards. Then, for each dimension that is being considered, the cards should be stacked in order of their performance on the related dimension. Next, there will be several rounds of sorting and debating that develop a consensus concerning the importance of each innovative idea or project. (Thomas \& Watson, 2002)

\section{Combining Qualitative and Quantitative Methods}

Managers can also combine qualitative and quantitative methods when choosing innovative projects. An approach that utilizes both qualitative and quantitative methods is Conjoint Analysis. Conjoint analysis estimates the relative value that individuals place on attributes of a choice. First, an individual is given a card with products that have different prices and features. These items are then rated in terms of desirability. Next, a multiple regression is performed to assess which attributes influence the rating.

A Data Envelopment Analysis (DEA) is another approach that combines quantitative and qualitative methods. A DEA uses linear programming to combine measures of the project that are based on different units into an efficiency frontier. In performing a DEA, projects can be ranked by assessing their distance from the efficiency frontier. The results of the Data Envelopment Analysis are only as good as the data that is utilized.

\section{PROTECTING INNOVATIVE TECHNOLOGY}

Firms must protect their innovations to retain control of the product or process. In regard to product protection, a firm may apply for a patent. A patent is a firm's rights granted by the government that excludes others from producing, using, or selling an invention (General Information, 2015). There are three different types of patents, which include Utility, Design, and Plant. A Utility patent protects new and useful processes, machines, and a combination of materials. A Design patent protects the original designs for manufactured items. A Plant patent protects distinct new varieties of plants. Other options for protecting products includes include trademarks and copyrights. A trademark is a word, phrase, symbol, or other indicator that is used to distinguish the source of goods from one party from another (General Information, 2015). An example of a trademark would be the Apple symbol. A copyright is a form of protection granted 
to works of authorship. A copyright it prohibits others from performing the work publicly, displaying the work publicly, and reproducing the work in copies or phone records. A copyright is established in first legitimate use. The copyright for works was created after 1978 to have protection for author's life plus 70 years.

\section{SUMMARY}

As time progresses, business managers will need to continue to embrace and participate in the growth of technology. This must occur as technological innovation is a key driver of firms' financial performance due to improved productivity and the creation of desirable technological products. In addition to improving the financial performance and security of individual firms, technological innovations also positively impact the economy due to increased output and product sales which improve the national GDP. To monitor the likelihood of the occurrence of new and needed technological innovations, CEOs and business managers must direct their teams in finding the most useful business life cycle approach for their company. In using a life cycle approach, businesses can track a current technology's progression, and initiate appropriate decision-making and transition strategies in coordination with the analyzed technology's maturation and inevitable decline. As a part of the transition period, new innovative and disruptive technologies can be adopted or created. These projects can be selected using quantitative, qualitative, or mixed methods. The resulting innovation could be categorized as a product, process, incremental, radical, competenceenhancing, competence-destroying, component or architectural innovation. If the new innovation is unique and exclusive to the creating firm, the item should be protected by a patent so that the firm can gain competitive advantage through their owned process or product.

\section{REFERENCES}

Anderson, P., \& Tushman, M.L. (1990). Technological discontinuities and dominant designs: A cyclical model of technological change. Administrative Science Quarterly, 35(4), 604-633. https://doi.org/10.2307/2393511

Broughel, J., \& Thierer, A. (2019). Technological innovation and economic growth: A brief report on the evidence. Mercatus Center. Retrieved from https://www.mercatus.org/publications/entrepreneurship/technological-innovation-and-economicgrowth

Bughin, J., \& Woetzel, J. (2020). Navigating a world of disruption. McKinsey \& Company. Retrieved from https://www.mckinsey.com/featured-insights/innovation-and-growth/navigating-a-world-ofdisruption

Çalışkan, H.K. (2015). Technological change and economic growth. Procedia - Social and Behavioral Sciences, 195, 649-654. https://doi.org/10.1016/j.sbspro.2015.06.174

Choudhury, N. (2014). World wide web and its journey from web 1.0 to web 4.0. International Journal of Computer Science and Information Technologies, 5(6), 8096-9100. Retrieved from http://citeseerx.ist.psu.edu/

Daft, R.L. (2021). Organization theory \& design. Boston, MA: Cengage.

Davis, F., Bagozzi, R., \& Warshaw, P. (1989). User acceptance of computer technology: A comparison of two theoretical models. Management Science, 35, 982-1003. https://doi.org/10.1287/mnsc.35.8.982

Forbes Technology Council. (2020, May 7). 15 technologies that will disrupt the industry in the next five years. Forbes. Retrieved from https://www.forbes.com/sites/forbestechcouncil/2020/05/07/15technologies-that-will-disrupt-the-industry-in-the-next-five-years/

Foster, R. (1986). Innovation: The attacker's advantage. New York, NY: McKinsey \& Company.

Frizzo-Barker, J., Chow-White, P.A., Adams, P.R., Mentanko, J., Ha, D., \& Green, S. (2020). Blockchain as a disruptive technology for business: A systematic review. International Journal of Information Management, 51. https://doi.org/10.1016/j.ijinfomgt.2019.10.014 
General Information Concerning Patents. (2015, October). United States Patent and Trademark Office. Retrieved from https://www.uspto.gov/patents-getting-started/general-information-concerningpatents

Gregory, P.R., \& Stuart, R.C. (2004). Comparing economic systems in the twenty-first century (7th ed.). Mason, OH: South-Western, Cengage Learning.

Gross Domestic Product, Third Quarter (Advance Estimate). (2020, October 29). Bureau of Economic Analysis - U.S. Department of Commerce. Retrieved from https://www.bea.gov/news/2020/gross-domestic-product-third-quarter-2020-advance-estimate

Gross Domestic Product. (n.d.). Bureau of Economic Analysis - U.S. Department of Commerce. Retrieved December 21, 2020, from www.bea.gov/resources/learning-center/what-to-know-gdp.

Hao, S., \& Song, M. (2016). Technology-driven strategy and firm performance: Are strategic capabilities missing links? Journal of Business Research, 69(2), 751-759. https://doi.org/10.1016/j.jbusres.2015.07.043

Kogan, L., Papanikolaou, D., Seru, A., \& Stoffman, N. (2017). Technological innovation, resource allocation, and growth. The Quarterly Journal of Economics, 132(2), 665-712. https://doi.org/10.1093/qje/qjw040

Kosta, A., Pappas, N., \& Angelakis, V. (2017). Age of information: A new concept, metric, and tool. Foundations and Trends in Networking, 12(3), 162-259. http://dx.doi.org/10.1561/1300000060

Levitt, T. (1965). Exploit the Product Life Cycle. Harvard Business Review. Retrieved from https://hbr.org/1965/11/exploit-the-product-life-cycle

Nieto, M., Lopéz, F., \& Cruz, F. (1998). Performance analysis of technology using the S curve model: The case of digital signal processing (DSP) technologies. Technovation, 18(6-7), 439-457. https://doi.org/10.1016/S0166-4972(98)00021-2

Pisano, G. (2015). You need an innovation strategy. Harvard Business Review. Retrieved from https://hbr.org/2015/06/you-need-an-innovation-strategy

Rogers, E.M. (2003). Diffusion of innovations (5th ed.). New York: Free Press.

Schilling, M.A. (2017). Strategic management of technological innovation (5th ed.). New York, NY: McGraw-Hill Education.

Snyder, B. (2019). How innovation drives economic growth. Stanford Graduate School of Business. Retrieved from https://www.gsb.stanford.edu/insights/how-innovation-drives-economic-growth

Taylor, M., \& Taylor, A. (2012). The technology life cycle: Conceptualization and managerial implications. International Journal of Production Economics, 140(1), 541-553. https://doi.org/10.1016/j.ijpe.2012.07.006

Thomas, D., \& Watson, R. (2002). Q-sorting \& MIS research: A primer. Communications of the Association for Information Systems, 8, 141-156. https://doi.org/10.17705/1CAIS.00809

Tushman, M.L., \& Anderson, P. (1986). Technological discontinuities and organizational environments. Administrative Science Quarterly, 31(3), 439-465. https://doi.org/10.2307/2392832

Weller, C. (2002). Learning lessons from the 1990s: Long-term growth prospects for the U.S. Economic Policy Institute. Retrieved from https://www.epi.org/publication/webfeatures_viewpoints_1t_growth_lessons/

World Development Indicators. (n.d.). The World Bank. Retrieved December 30, 2020, from https://databank.worldbank.org/reports.aspx?source=world-development-indicators 